\title{
Vulnerabilidade a perdas habitacionais na Região Metropolitana de São Paulo
}

\author{
Anderson Kazuo Nakano*
}

0 presente trabalho tem como objetivo estimar a população vulnerável a perdas habitacionais residente na Região Metropolitana de São Paulo (RMSP). Para isso utilizam-se os microdados da amostra do Censo Demográfico de 2010 produzido pelo Instituto Brasileiro de Geografia e Estatística (IBGE). São selecionados os microdados sobre renda familiar, espécies e tipos de domicílios e condições de ocupação de domicílios particulares permanentes com base em premissas teóricas e conceituais relativas a "deslocabilidade" (displaceability) (YIFTACHEL, 2017), insegurança e alienação habitacional (MADDEN; MARCUSE, 2016), transitoriedade permanente (ROLNIK, 2015), gentrificação e rent gap (SMITH, 2010) e gentrificação e value gap (HAMNETT; RANDOLPH, 1986 apud LEES et al., 2008). 0 cálculo da estimativa da população “deslocalizável” e vulnerável a perdas habitacionais residente na RMSP resulta em 3.423.265 pessoas (2010).

Palavras-chave: “Deslocabilidade”.Vulnerabilidade. Perda habitacional. Região Metropolitana de São Paulo.

\footnotetext{
* Universidade Federal de São Paulo (Unifesp), São Paulo-SP, Brasil (kazuo.nakano@gmail.com; https://orcid.org/00000002-1929-5270).
} 


\section{Introdução}

0 ato de habitar envolve necessariamente estar em um lugar no qual se vive e muitas vezes se convive com outras pessoas. Habitar um lugar é ter ligações especiais com elementos que compõem esse lugar, inclusive seus habitantes. Ligações objetivas e subjetivas, materiais e imateriais, tangíveis e intangíveis constituem o ato de habitar. Assim, a perda habitacional implica inevitavelmente a perda de um lugar, a saída de um local, o deslocamento, a deslocalização. Implica também desligamentos. Nesse sentido, a vulnerabilidade à perda habitacional pode ser compreendida a partir do conceito de displaceability, elaborado por Oren Yiftachel (2017) e descrito mais detalhadamente adiante. Seguindo Ananya Roy e Raquel Rolnik (2020, p. 24), podemos denominar esse conceito com o termo "deslocabilidade", considerando-o como parte do "repertório expandido de metodologias de pesquisa para a justiça habitacional” (ROY; ROLNIK, 2020, p. 19).

Em diferentes cidades brasileiras, bem como em outras partes do mundo, populações sujeitas à "deslocabilidade”, ou seja, populações "deslocalizáveis”, sofrem diante das ocorrências frequentes de perdas e despossessões habitacionais que violam e negam a moradia como direito social e humano. Perante esta constatação, o presente trabalho tem como objetivo apresentar a aplicação de um método criado especificamente para estimar a população “deslocalizável”, portanto vulnerável a perdas habitacionais, residente na Região Metropolitana de São Paulo (RMSP), a partir dos microdados da amostra do Censo Demográfico 2010 do Instituto Brasileiro de Geografia e Estatística (IBGE).

Esse modo de colocação da problemática habitacional a partir da "deslocabilidade" e perda do local de moradia contrasta com o modelo tradicional de colocação desta problemática baseado recorrentemente na ideia de déficit habitacional que, em vez de perdas, aponta para a necessidade de ganhos e acréscimos no estoque de moradias. Em trabalho que visa expor criticamente a construção histórica da problemática habitacional que "deu forma ao déficit habitacional", Nascimento e Braga (2009) mostram como o modo tradicional de colocação daquela problemática baseada na ideia de déficit habitacional persistiu nos discursos de especialistas durante boa parte do século XX, principalmente a partir da década de 1930. Essa persistência consolidou as abordagens quantitativas que continuam sendo utilizadas nos debates públicos e na formulação e implementação de programas habitacionais de diferentes níveis de governo. As autoras mostram que, desde a segunda metade da década de 1920, "a habitação é apresentada publicamente como uma deficiência numérica que deve e pode ser mensurada e igualmente revertida" (NASCIMENTO; BRAGA, 2009, p. 100).

Os cálculos do déficit habitacional no Brasil são caudatários do modo de apresentação da problemática habitacional como "deficiência numérica que deve ser mensurada e igualmente revertida”. Dentre esses cálculos destaca-se a série elaborada por equipes da 
Fundação João Pinheiro (FJP) iniciada em 1995 e com atualização mais recente em 2018. ${ }^{1}$ Tais cálculos utilizam os microdados da Pesquisa Nacional por Amostra de Domicílios e Censo Demográfico, ambos levantamentos produzidos pelo IBGE.

Ao discutirem as diferenças e semelhanças entre os conceitos e definições de família, domicílio e condições habitacionais nos Censos Demográficos da Argentina, Brasil e Estados Unidos, Alves e Cavenaghi (2005) mostram que o déficit habitacional baseia-se no "balanço habitacional", no qual se subtrai o total de famílias do total de domicílios. Os autores esclarecem que o déficit habitacional ocorre quando o total de domicílios é menor do que o total de famílias, enquanto o superávit se dá quando o total de domicílios é maior do que o total de famílias.

Além de mostrarem as necessidades atuais de novas moradias, os cálculos do déficit habitacional no Brasil elaborados pela FJP serviram como referência para a projeção futura das "demanda demográfica por moradia" mensurada por Oliveira, Givisiez e Rios-Neto (2009) para o extinto Ministério das Cidades. Segundo os autores, "A demanda demográfica por moradias é a quantidade de unidades residenciais necessárias para atender todas as famílias que irão efetivamente formar um novo domicílio" (OLIVEIRA; GIVISIEZ; RIOS-NETO, 2009, p. 14, grifo dos autores). Para projetar a "demanda demográfica por moradias" no futuro, os autores utilizaram a "taxa de chefia de domicílios" assumida como tendo correlação positiva com a "taxa de formação de novas moradias" (OLIVEIRA; GIVISIEZ; RIOS-NETO, 2009, p. 18).

A elaboração de uma estimativa da população “deslocalizável” e vulnerável a perdas habitacionais se justifica, em primeiro lugar, pelo simples fato de que não há um dimensionamento e uma caracterização daquela população na metrópole de São Paulo. Essa população está invisível e oculta sob camadas de representações e interpretações relativas às suas condições de vida. Na maioria das vezes, ganha visibilidade pública quando ocorrem desastres e nos momentos em que a "deslocabilidade" e a perda habitacional estão prestes a se efetivar ou quando se efetivam em meio a conflitos que, de maneira geral, contrapõem os agentes do Estado e da sociedade. Em segundo lugar, aquela estimativa é importante porque existe a necessidade de referências para a adoção de medidas capazes de prevenir, evitar e compensar a ocorrência desse tipo de "deslocalização" e perda habitacional que, em muitos casos, destroem as condições de vida das pessoas afetadas, instaurando uma cadeia de efeitos e desdobramentos igualmente deletérios e destrutivos.

Vale esclarecer que a população “deslocalizável” e vulnerável à perda habitacional considerada neste trabalho pode ou não vir a sofrer com essas ocorrências. Isso depende dos contextos e das condições nas quais essas populações vulneráveis vivem. Em determinados contextos, as condições socioeconômicas, sociodemográficas e de ocupação habitacional podem tornar tal população “deslocalizável” e vulnerável àquelas perdas. Por exemplo, nos contextos em que: moradores se veem diante das impossibilidades de

\footnotetext{
${ }^{1}$ Além desse cálculo divulgado em 1995, a FJP atualizou os números do déficit habitacional no Brasil em 2001, 2004, 2005, 2006, 2009, 2011, 2012, 2013 (déficit habitacional municipal no Brasil), 2015, 2016, 2017 e 2018.
} 
continuar pagando as prestações relativas à aquisição de suas habitações; haja aumento de aluguéis por conta do encarecimento de imóveis e do custo de vida em áreas cobiçadas por investidores do mercado imobiliário; ocorram desapropriações causadas pela realização de obras públicas; aconteça a execução de ações de reintegração de posse decididas em favor de proprietários de áreas ocupadas com moradias de populações vulneráveis de baixa renda, dentre outras situações.

No presente trabalho, admite-se hipoteticamente que a população de baixa renda que vive em determinadas condições de posse e ocupação domiciliar inserida nos contextos mencionados no parágrafo anterior pode ser "deslocalizável” e estar mais vulnerável a sofrer perda habitacional. Supõe-se que a população de baixa renda que não possui a propriedade plena das suas moradias pode ser "deslocalizável” e estar mais vulnerável àquela perda. Essa hipótese norteou a seleção de variáveis do banco de microdados da amostra do Censo Demográfico 2010 do IBGE, em que pese o fato de que a propriedade privada individualizada do domicílio não evita a "deslocabilidade" e a perda habitacional involuntária. Assim, a estimativa da população “deslocalizável” e vulnerável à perda habitacional baseia-se na caracterização das suas condições domiciliares, socioeconômicas e sociodemográficas. A seguir apresentam-se os subgrupos populacionais calculados a partir de variáveis selecionadas do banco de microdados da amostra do Censo Demográfico 2010, que compõem a totalidade daquela estimativa da população vulnerável à perda habitacional residente na Região Metropolitana de São Paulo (RMSP) em 2010.

\section{Referências conceituais e metodológicas para a mensuração da população deslocalizável e vulnerável a perdas habitacionais}

Segundo Oren Yiftachel (2017, tradução nossa), a “deslocabilidade” (displaceability) consiste na "suscetibilidade de pessoas, grupos e empreendimentos a serem removidos, expulsos e impedidos de exercerem seu direito à cidade". ${ }^{2}$ Trata-se, segundo o autor, de uma "condição sistêmica a partir da qual o poder marginalizador é exercido por meio de sistemas políticos e jurídicos". ${ }^{3}$ Para o autor, a ameaça da "deslocabilidade" é o fundamento da cidadania contemporânea.

Dado o recente aumento na insegurança habitacional, econômica e política, essa ameaça pode ser vista como uma "fundação silenciosa" da cidadania urbana contemporânea. Portanto, pode-se observar que quanto maior a ameaça de deslocalização, mais frágil a cidadania urbana ${ }^{4}$ (YIFTACHEL, 2017, tradução nossa).

\footnotetext{
${ }^{2}$ No original em inglês: "susceptibility of people, groups and developments to be removed, expelled or prevented from exercising their right to the city".

${ }^{3}$ No original em inglês: "systemic condition through which marginalizing power is exerted through policy and legal systems".

${ }^{4}$ No original em inglês: "Given the recent global rise in housing, economic and political insecurity, this threat can be seen as a 'silent foundation' of contemporary urban citizenship. Accordingly, one may observe that the greater the threat of displacement, the weaker the urban citizenship".
} 
Podemos assumir que, ao serem suscetíveis a remoções, expulsões e violações no seu direito à cidade, as pessoas “deslocalizáveis" são vulneráveis a perdas dos seus locais de moradia e, portanto, fazem parte da população vulnerável à perda habitacional, cujas características e dimensionamentos são os focos centrais deste trabalho. Portanto, no presente artigo, pretende-se mensurar a população “deslocalizável” vulnerável à perda habitacional.

Segundo Yiftachel (2017, tradução nossa), a “deslocabilidade” deriva da realização de "regimes urbanos contemporâneos que não somente alocam, mas também ameaçam, enfraquecem e negam direitos e capacidades urbanas". ${ }^{5}$ Nota-se que tais "regimes urbanos" envolvem processos, ações e relações de controles e disputas sobre locais da cidade. Não faz parte do escopo deste trabalho analisar os "regimes urbanos" nos quais a "deslocabilidade" efetiva-se em “deslocalização" e perda concreta de locais de moradia. 0 objetivo aqui é somente apresentar a metodologia utilizada para mensurar a população “deslocalizável” e vulnerável à perda habitacional. Essa mensuração baseia-se nos microdados da amostra do Censo Demográfico 2010, os quais caracterizam os moradores dos domicílios pesquisados a partir do seu perfil sociodemográfico, migratório e habitacional. Esses microdados foram utilizados para traçar os perfis sociodemográficos e habitacionais daqueles moradores "deslocalizáveis" supostamente em situação de vulnerabilidade à perda habitacional.

Para selecionar os microdados da amostra do Censo Demográfico de 2010, assumiram-se alguns pressupostos sobre os perfis sociodemográficos e habitacionais dos moradores da RMSP que supostamente indicam condições de “deslocabilidade" e vulnerabilidade à perda habitacional. Tais pressupostos referem-se basicamente à inexistência ou insuficiência de recursos mobilizáveis no enfrentamento dessa perda.

0 estabelecimento daqueles pressupostos foi o ponto de partida do raciocínio a respeito das possíveis características da população “deslocalizável” e vulnerável à perda habitacional residente na RMSP. Cada pressuposto norteou a avaliação de um conjunto de características sociodemográficas e habitacionais levantadas pelos microdados do Censo. Cada avaliação serviu para verificar até que ponto estes microdados poderiam ser utilizados para indicar, de modo aproximado, as características da população "deslocalizável” e vulnerável à perda habitacional. Portanto, a definição das características básicas dessa população e a seleção dos microdados ocorreram simultaneamente, em um processo de condicionamento mútuo. Assim, as variáveis daqueles microdados determinaram a definição dos componentes utilizados na estimativa da população "deslocalizável” e vulnerável à perda habitacional residente na RMSP. Tais variáveis são:

- insuficiência de renda familiar para o acesso habitacional;

\footnotetext{
${ }^{5}$ No original em inglês: "contemporary urban regimes do not only allocate, but also threaten, weaken and deny urban rights and capabilities".
} 
- condições de ocupação domiciliar que diferem da propriedade quitada do imóvel habitacional, ${ }^{6}$ levando tais populações a serem, supostamente, "deslocalizáveis" e, portanto, vulneráveis à perda habitacional.

Conforme descrições detalhadas apresentadas adiante, as variáveis definidas, a partir de cruzamentos entre microdados da amostra do Censo Demográfico de 2010, para quantificar os subgrupos populacionais que compõem a população “deslocalizável” e vulnerável à perda habitacional são:

- pessoas de baixa renda (com renda familiar mensal de até $\mathrm{R} \$ 1.600,00$ ) moradoras de domicílios particulares permanentes "próprio de algum morador - ainda pagando", “alugado", “cedido pelo empregador”, “cedido de outra forma” e com "outra condição" de ocupação;

- pessoas moradoras de domicílio particular improvisado;

- pessoas moradoras de domicílio coletivo.

Supõe-se que essas variáveis indicam impossibilidades de acesso, dificuldades de permanência e possibilidades de perda em relação aos locais de moradia. Perda que pode vir a ocorrer em casos de eventuais choques e riscos advindos de mudanças no contexto urbano que podem vir a impor dificuldades de continuar morando no local, seja devido a aumentos nos custos de vida, seja por causa de remoções forçadas realizadas por meio de despejos, reintegrações de posse, desapropriações, expulsões, banimento, dentre outros modos de "deslocalização" e perda habitacional.

Dentre as perdas e destituições que uma determinada população pode sofrer, a "deslocalização" e a perda habitacional estão entre as mais sérias, pois significam a destruição de um dos seus recursos mais importantes que pode ser mobilizado na luta por proteção contra fatores adversos e no enfrentamento aos riscos originários de crises produzidas por macros e microprocessos locais e extralocais. Por exemplo, diante dos choques produzidos pelo desemprego e pobreza que acarretam uma série de efeitos prejudiciais às condições de vida daquela população, a habitação serve tanto como um abrigo quanto como um recurso que pode ser utilizado econômica e produtivamente na realização de atividades que podem ajudar tais moradores a gerar algum tipo de renda necessária à sua sobrevivência. A habitação adequada, com boas condições de habitabilidade e bem localizada na cidade, coloca-se como um "colchão" de proteção social e contribui para eliminar ou reduzir a vulnerabilidade dos seus moradores.

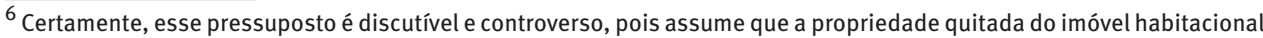
assegure proteção contra os riscos e ameaças de "deslocalização", despossessões e perdas habitacionais, o que pode não ser verdade, considerando-se os diversos casos, muitas vezes arbitrários, de despejos, remoções, expulsões, dentre outros processos, que afetaram moradores com a propriedade plena dos seus imóveis habitacionais. Ademais, os dados relativos à propriedade dos domicílios próprios colhidos por pesquisadores do IBGE para o Censo Demográfico 2010 possuem imprecisões em relação à regularidade e segurança jurídica e administrativa de tal propriedade imobiliária. No Brasil, não há um cadastro completo, atualizado e unificado de todas as propriedades imobiliárias urbanas ou rurais com dados dos seus respectivos proprietários.
} 
A "deslocabilidade" e a perda habitacional estão entre as mais sérias vulnerabilidades, pois apontam para a existência de várias outras vulnerabilidades originárias da insuficiência de recursos necessários ao enfrentamento de choques e riscos que podem emergir da reestruturação urbana e do aquecimento dos mercados fundiários e imobiliários, bem como de crises políticas, econômicas, sociais, ambientais, dentre outras. A "deslocalização" e a perda habitacional se desdobram em uma longa cadeia de outras perdas sociais, materiais, existenciais e subjetivas.

Neste começo do século XXI, quando as terras, localizações, imóveis e moradias urbanas tornam-se ativos financeiros valiosos, testemunhamos diariamente a "deslocalização" habitacional e perdas em cadeia sofridas por populações vulneráveis e de baixa renda que se submetem às destruições, em larga escala, das suas condições básicas de vida marcadas pelas situações de pobreza e miséria. A seguir, apresenta-se o conjunto de raciocínios teóricos e conceituais que nortearam a escolha dos microdados da amostra do Censo Demográfico de 2010 utilizados na mensuração dos subgrupos que compõem a estimativa da população “deslocalizável” e vulnerável à perda habitacional residente na RMSP.

\section{A insuficiência de renda familiar para 0 acesso habitacional}

O primeiro pressuposto adotado na seleção dos microdados utilizados na estimativa da população “deslocalizável” e vulnerável a perdas habitacionais baseia-se na insuficiência da renda necessária para acessar e se manter na habitação. Considerou-se que os grupos populacionais que não possuem renda familiar suficiente para satisfazer adequadamente suas necessidades habitacionais também são “deslocalizáveis” e vulneráveis a perdas habitacionais quando, em determinados contextos urbanos, sociais, políticos, econômicos e ambientais, aquela insuficiência de renda é combinada com outros fatores que agravam a insegurança na condição de ocupação da moradia. Entende-se que essa combinação de fatores leva à "deslocalização" e à perda habitacional.

Além da impossibilidade de acesso ao mercado habitacional, a insegurança na condição de ocupação habitacional de grande parte da população com baixos rendimentos deve-se também às limitadas provisões habitacionais produzidas por meio de programas coordenados pelo poder público. Estes não satisfazem as necessidades de muitos membros daqueles grupos que, desse modo, se veem obrigados a buscar alternativas de moradia utilizando os próprios recursos ou a partir de favores obtidos de outrem. Em geral, tais alternativas são precárias, com condições urbanas e habitacionais ruins. Nessas alternativas, a posse da terra e do imóvel habitacional ocorre de modo muitas vezes informal e inseguro em loteamentos e ocupações irregulares. Não raramente, essas alternativas se localizam em áreas urbanas periféricas, distantes das "estruturas 
de oportunidades"7 urbanas concentradas, na maioria das vezes, nas áreas centrais das cidades.

Porém, estas áreas centrais também possuem alternativas precárias, irregulares e inseguras de moradia acessadas pelos grupos populacionais com baixos rendimentos, como, por exemplo, as favelas centrais, os cortiços, as pensões, as ocupações de terrenos e prédios ociosos, os domicílios improvisados, dentre outras. Tais áreas são também os lugares onde se concentra a maior parte da crescente população em situação de rua que sequer acessa aquelas alternativas habitacionais precárias, irregulares e inseguras e, desse modo, sobrevive em condições limites de "deslocabilidade" e vulnerabilidade.

Diante da importância da renda familiar no acesso e permanência habitacional, adotou-se a insuficiência de rendimentos como primeiro pressuposto em relação à vulnerabilidade a perdas habitacionais e, portanto, como critério básico de seleção dos microdados utilizados na estimativa da população “deslocalizável” e vulnerável a essas perdas. Esse pressuposto traz imediatamente uma segunda questão importante relativa à definição do nível de rendimento considerado suficiente para satisfazer a necessidade habitacional.

As questões concernentes à necessidade habitacional e à insuficiência de renda para o acesso à moradia levam a reflexão em direção à discussão sobre o cálculo do déficit habitacional. Um dos cálculos mais conhecidos é aquele elaborado pela Fundação João Pinheiro, órgão do governo estadual de Minas Gerais dedicado ao ensino e pesquisa. Essa instituição calcula o déficit habitacional brasileiro desde meados da década de 1990, utilizando os microdados da Pesquisa Nacional por Amostra de Domicílios (PNAD) e do Censo Demográfico, ambos produzidos pelo IBGE. Em 2010, o cálculo do déficit habitacional brasileiro foi feito pela Fundação João Pinheiro a partir dos microdados da amostra do Censo Demográfico produzido naquele ano. Tal cálculo mostrou que $66,6 \%$ do déficit de novas moradias correspondiam às necessidades habitacionais de pessoas que viviam em domicílios sem rendimentos ou com renda inferior a três salários mínimos (FUNDAÇÃO JOÃO PINHEIRO, 2018). Isso significa que a maior parte das pessoas que não satisfaziam suas necessidades habitacionais possuía renda familiar menor ou igual a três salários mínimos.

Além da informação a respeito do déficit habitacional brasileiro, levou-se em conta, na definição do nível insuficiente de renda para satisfazer a necessidade habitacional, o valor máximo da renda familiar dos beneficiários do Programa Minha Casa Minha Vida ${ }^{8}$ (PMCMV) definidos na Lei n. 11.977/2009 e alterados pela Lei n. 12.424/2011. Ambas

\footnotetext{
${ }_{7}$ Rubem Katzman e Fernando Filgueira (2006, p. 72) definem as estruturas de oportunidades "em termos de oportunidades de acesso a bens, serviços ou atividades que incidem sobre o bem-estar dos domicílios, seja porque os fazem usar seus próprios recursos mais facilmente seja porque lhes possibilitam outros, úteis para que integrem a sociedade por meio dos canais existentes".

${ }^{8}$ Esse Programa foi lançado no início de 2009 pelo governo federal como medida anticíclica prevista para enfrentar os efeitos da crise econômica de 2008 originária dos Estados Unidos e que logo se expandiu em direção a outros países do mundo. Atualmente (2021), o Programa Minha Casa Minha Vida foi substituído pelo Programa Casa Verde Amarela que não atende às necessidades habitacionais das famílias de baixa renda inseridas na faixa 1 .
} 
as leis dispõem sobre aquele programa habitacional e sobre a regularização fundiária de assentamentos irregulares localizados em áreas urbanas.

De acordo com o parágrafo 6 , da Lei n. $12.424 / 2011$, as rendas familiares dos beneficiários não deveriam ultrapassar os limites de dez (inciso I), seis (inciso II) e três salários mínimos (inciso III). Tais limites correspondem aos valores máximos das faixas de rendimento familiar que determinam os grupos de beneficiários atendidos pelo PMCMV. Para a estimativa da população “deslocalizável” e vulnerável a perdas habitacionais, interessa particularmente o limite de três salários mínimos que corresponde ao valor máximo da renda familiar dos beneficiários atendidos na faixa 1. Do ponto de vista do PMCMV, as famílias com rendimento familiar inferior àquele valor não tinham renda suficiente para adquirir suas moradias e, portanto, necessitavam de subsídio público integral para satisfazer suas necessidades habitacionais. Supõe-se, por conseguinte, que aquelas famílias com rendimentos insuficientes para adquirir suas moradias encontravam-se vulneráveis a perdas habitacionais. Em 2011, quando o valor do salário mínimo brasileiro era igual a $\mathrm{R} \$ 540,00$, o limite máximo da renda familiar dos beneficiários atendidos pelo PMCMV, segundo os critérios e exigências da faixa 1 , era de $R \$ 1.600,00$, valor um pouco menor do que os $R \$ 1.620,00$ equivalentes a três salários mínimos naquele ano.

Adotando o mesmo ponto de vista do PMCMV, considerou-se a renda familiar de até $\mathrm{R} \$ 1.600,00$ como a referência básica para definir a insuficiência de rendimentos que impede 0 acesso habitacional e, portanto, contribui para a vulnerabilidade de determinados grupos populacionais a perdas habitacionais. Supõe-se que os grupos com renda familiar de até $R \$ 1.600,00$ podem ser “deslocalizáveis” e estar vulneráveis àquelas perdas porque seus baixos rendimentos, associados às condições inseguras de ocupação domiciliar, não asseguram as condições para enfrentar os impactos de despejos, expulsões, reintegrações de posse, aumentos nos custos de vida e nos valores de aluguéis e prestações, dentre outros fatores.

Decerto que há alguma arbitrariedade na decisão de adotar o valor de $\mathrm{R} \$ 1.600,00$ como a referência para a determinação da insuficiência de renda familiar que inviabiliza o acesso à habitação adequada e produz condições de “deslocabilidade" e vulnerabilidade a perdas habitacionais. Contudo, acredita-se que tal decisão está bem fundamentada em informações consistentes relativas ao déficit habitacional brasileiro e aos critérios de atendimento do PMCMV. A população com renda familiar menor ou igual a $\mathrm{R} \$ 1.600,00$ corresponde à maior parte daquele déficit e é a que deve ser integralmente subsidiada no atendimento habitacional por ser a que mais necessita de ajuda do poder público para ter acesso à habitação adequada.

Em 2010, as pessoas com baixos rendimentos familiares representavam 43,5\% (8.561.914 pessoas) da população total da Região Metropolitana de São Paulo (RMSP). O Mapa 1 mostra a distribuição dessa população entre os municípios da região e os distritos do município de São Paulo (MSP). Mais de 50\% dos habitantes dos municípios 
localizados nos extremos das porções leste, nordeste, noroeste e sudoeste da RMSP possuíam rendimentos familiares menores ou iguais a $R \$ 1.600,00$. No MSP tal percentual encontrava-se nos extremos das periferias leste e sul, em distritos como Iguatemi e Parelheiros, respectivamente.

\section{MAPA 1}

Distribuição da população com renda familiar menor ou igual a R\$ $1.600,00$ Região Metropolitana de São Paulo - 2010

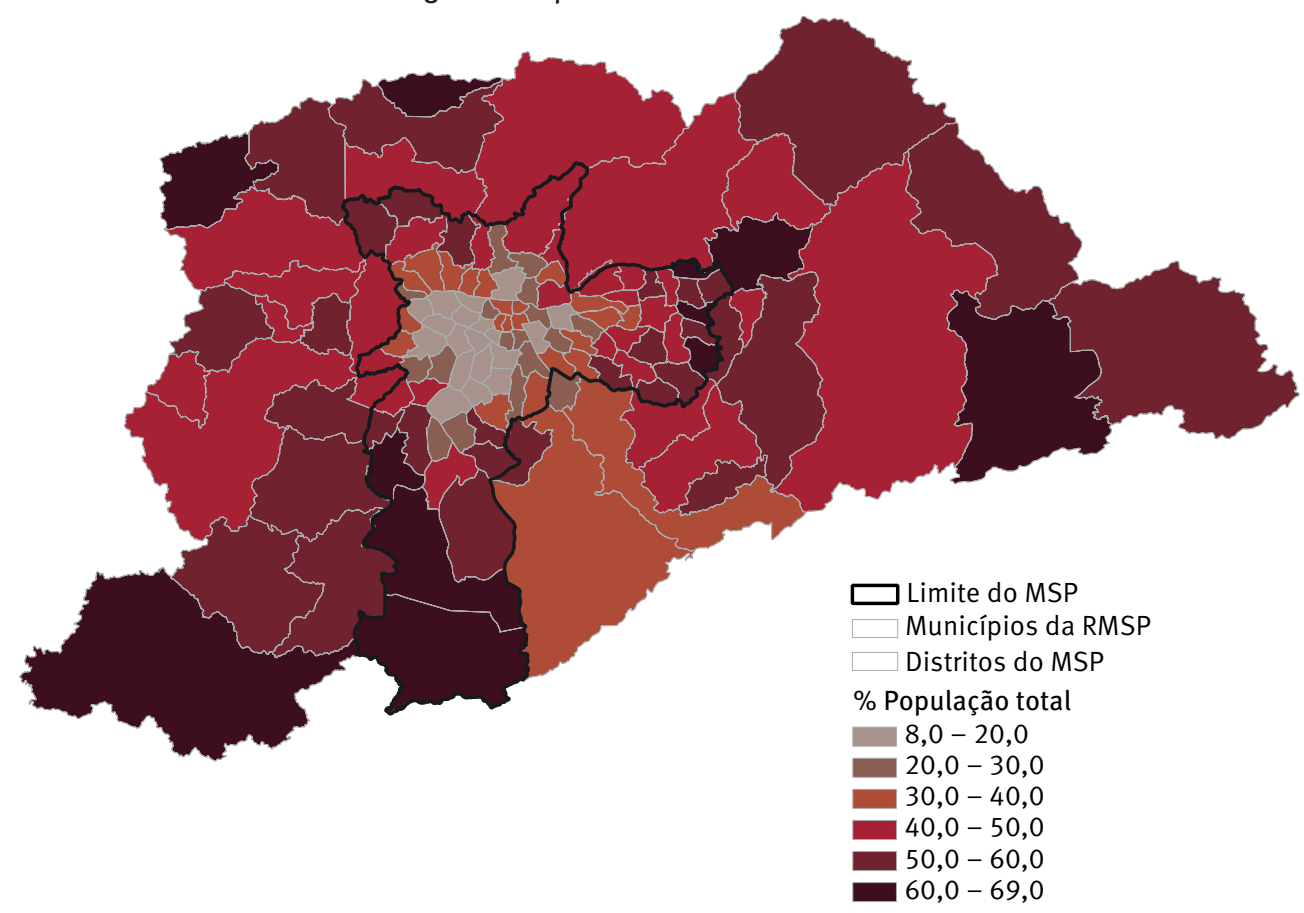

Fonte: IBGE. Censo Demográfico 2010.

Conforme mencionado anteriormente, a insuficiência de renda para o acesso e permanência habitacional resulta em perdas habitacionais quando associada a condições inseguras e vulneráveis de ocupação da moradia. A situação na qual o morador ocupa e tem a posse da sua habitação é fator-chave na determinação da sua resistência ou vulnerabilidade à "deslocabilidade” e a perdas habitacionais. Dependendo dessa condição, o morador pode ser mais ou menos vulnerável a tais perdas. Segundo Raquel Rolnik (2016), a insegurança na ocupação e posse da habitação está na base da "permanente transitoriedade" vivida pela população de baixa renda exposta a riscos e ameaças de despossessões territoriais, o que invariavelmente resulta naquelas perdas habitacionais provocadas por processos de remoções. Mas como mensurar a população que vive em condições inseguras de ocupação e posse habitacional e, portanto, de "deslocabilidade" e vulnerabilidade à perda habitacional? 
Na seção seguinte são apresentadas as premissas que nortearam a seleção das variáveis do banco de microdados do Censo Demográfico 2010 relativas às condições de ocupação domiciliar, a partir das quais se quantificou o número daqueles moradores residentes na RMSP.

\section{As condições supostamente “deslocalizáveis” e vulneráveis na ocupação de domicílios particulares permanentes}

Os microdados da amostra do Censo Demográfico IBGE de 2010, fonte básica deste trabalho, não trazem a quantidade de pessoas que vivem em situação de insegurança na ocupação e na posse das suas respectivas habitações. No Brasil, não há informações precisas a esse respeito. Os dados do IBGE relativos à irregularidade fundiária dos domicílios brasileiros são extremamente subdimensionados, pois são obtidos a partir da declaração dos moradores desses domicílios que, geralmente, não possuem conhecimento claro a respeito da regularidade ou irregularidade nas documentações, titulações e registros jurídicos, administrativos e cartoriais referentes à propriedade dos lotes ocupados por aqueles domicílios. Por isso, é impossível dimensionar com precisão o tamanho da população brasileira que vive em situação de insegurança na ocupação e posse habitacional ocasionada pela irregularidade fundiária dos lotes ou terrenos ocupados por suas habitações. Diante de tal impossibilidade, o que fazer para quantificar a população "deslocalizável” e vulnerável a perdas habitacionais a partir da insegurança na ocupação e posse habitacional?

A alternativa foi elaborar estimativas a partir de alguns pressupostos mais ou menos aceitáveis a respeito das condições de ocupação das habitações, cujos moradores possam ser considerados inseguros, "deslocalizáveis" e vulneráveis a perdas habitacionais. Assim, na seleção dos microdados da amostra do Censo Demográfico de 2010 utilizados na construção da estimativa da população “deslocalizável” e vulnerável a tais perdas, adotou-se um pressuposto baseado nas condições de ocupação de domicílios particulares permanentes. Supôs-se que os moradores de baixa renda (com renda familiar mensal de até $\mathrm{R} \$ 1.600,00$ definida segundo raciocínio apresentado anteriormente) de domicílios particulares permanentes “próprio de algum morador - ainda pagando”, “alugado”, “cedido pelo empregador”, “cedido de outra forma” e com “outra condição” de ocupação podem ser "deslocalizáveis” e vulneráveis a perdas habitacionais, dependendo dos choques, riscos e ameaças produzidos em determinados contextos urbanos, políticos, econômicos e ambientais, dentre outros, que podem desencadear processos de despossessão habitacional.

Além dos moradores de domicílios particulares improvisados e de domicílios coletivos presentes em pequenas quantidades, ${ }^{9}$ a estimativa da população "deslocalizável” e

\footnotetext{
${ }^{9}$ A baixa participação dos moradores dos domicílios improvisados e coletivos no total de 3.423 .265 pessoas que compõem a estimativa da população vulnerável a perdas populacionais residente na RMSP faz com que não nos detenhamos nesses grupos populacionais no presente trabalho. Os moradores da primeira espécie de domicílios correspondem a $0,3 \%$ daquela população e os residentes da segunda equivalem a $2,0 \%$.
} 
vulnerável a perdas habitacionais inclui também os moradores dos domicílios particulares permanentes ocupados nas condições mencionadas no parágrafo anterior. Essa espécie de domicílios particulares abriga a maior parte da população brasileira. Considerou-se, hipoteticamente, que os moradores que vivem em algumas dessas condições podem ser considerados “deslocalizáveis" e vulneráveis a perdas habitacionais, caso seus locais de moradia sejam impactados por processos de valorização fundiária e imobiliária, aumentos nos valores das prestações para aquisição da moradia, elevação nos preços de aluguéis, realização de grandes obras de infraestrutura urbana que acarretam desapropriações, execução das ações de reintegração de posses, dentre outros fatores.

Moradores "deslocalizáveis" e vulneráveis a perdas habitacionais em domicílios particulares permanentes "próprios de algum morador - ainda pagando"

A suposta "deslocabilidade" e vulnerabilidade dos moradores de baixa renda que vivem em domicílio "próprio de algum morador - ainda pagando" baseia-se no risco de perda habitacional ocasionada por certa insegurança na condição de ocupação e posse da moradia. Essa insegurança se manifesta concretamente quando tal perda ocorre devido à incapacidade daqueles moradores de continuar arcando com o pagamento das prestações referentes à aquisição do imóvel. Pressupõe-se, portanto, que esses moradores são "deslocalizáveis" e vulneráveis a perdas habitacionais porque o atraso e a não quitação dos pagamentos das prestações relativas à aquisição do imóvel podem expô-los a despejos. Choques nas conjunturas políticas, sociais, econômicas ou ambientais podem levar à inadimplência em relação aos pagamentos das prestações.

Para a seleção dos microdados utilizados na estimativa da população vulnerável a perdas habitacionais, pressupôs-se que, nas cidades brasileiras, os moradores de baixa renda que vivem em domicílio particular permanente "próprio de algum morador - ainda pagando" sejam vulneráveis a tais perdas, caso não tenham recursos e ativos para lidar com a inadimplência no pagamento das prestações para a aquisição do imóvel. Utilizando o raciocínio de Moser (1997) e Katzman e Filgueira (2006), pode-se dizer que essa vulnerabilidade depende das capacidades dos moradores em mobilizar tais recursos e ativos para enfrentar e superar os riscos associados àquela inadimplência. Caso não consigam mobilizar recursos para enfrentar tais riscos, esses moradores podem vir a sofrer perdas habitacionais.

Nesse sentido, podemos relacionar a "deslocabilidade" e vulnerabilidade à perda habitacional com a "alienação residencial" discutida por Madden e Marcuse (2016) no tocante à situação na qual os moradores não se sentem em casa (not feel at home) vivendo em suas moradias. Assim, a "alienação residencial” surge quando os moradores de uma habitação ainda não quitada vivem sob o risco de perdê-la, seja devido à inadimplência no pagamento das prestações relativas à aquisição do imóvel, seja por causa de outras condições de insegurança nas formas de ocupação e posse habitacional. 
Assim, pressupõe-se que a "deslocabilidade" e a vulnerabilidade ante aos riscos de perdas habitacionais, a “alienação residencial” e os processos de despossessão territorial sofridos pelos moradores de baixa renda entrelaçam-se formando uma rede de insegurança habitacional que envolve principalmente os moradores de baixa renda que vivem em domicílio particular permanente "próprio de algum morador - ainda pagando". Os moradores de domicílios ainda não quitados correspondem a 15,1\% (518.471 pessoas) da população vulnerável a perdas populacionais estimada.

O Mapa 2 mostra a distribuição espacial desses moradores que se concentram principalmente nos distritos periféricos do MSP reconhecidos pela presença marcante de grandes conjuntos habitacionais de interesse social promovidos pelo poder público, tanto no âmbito do Sistema Financeiro da Habitação (SFH) durante a atuação do extinto Banco Nacional de Habitação (BNH) quanto pela Companhia de Desenvolvimento Habitacional e Urbano (CDHU) do governo estadual de São Paulo. Trata-se dos distritos Jaraguá, na parte noroeste do município, Cidade Tiradentes, Iguatemi, Itaim Paulista e José Bonifácio, localizados na parte leste, e Jaguaré, Morumbi e Raposo Tavares, na parte oeste.

MAPA 2

Distribuição da população vulnerável a perdas habitacionais em domicílio particular permanente próprio de algum morador - ainda pagando

Região Metropolitana de São Paulo - 2010

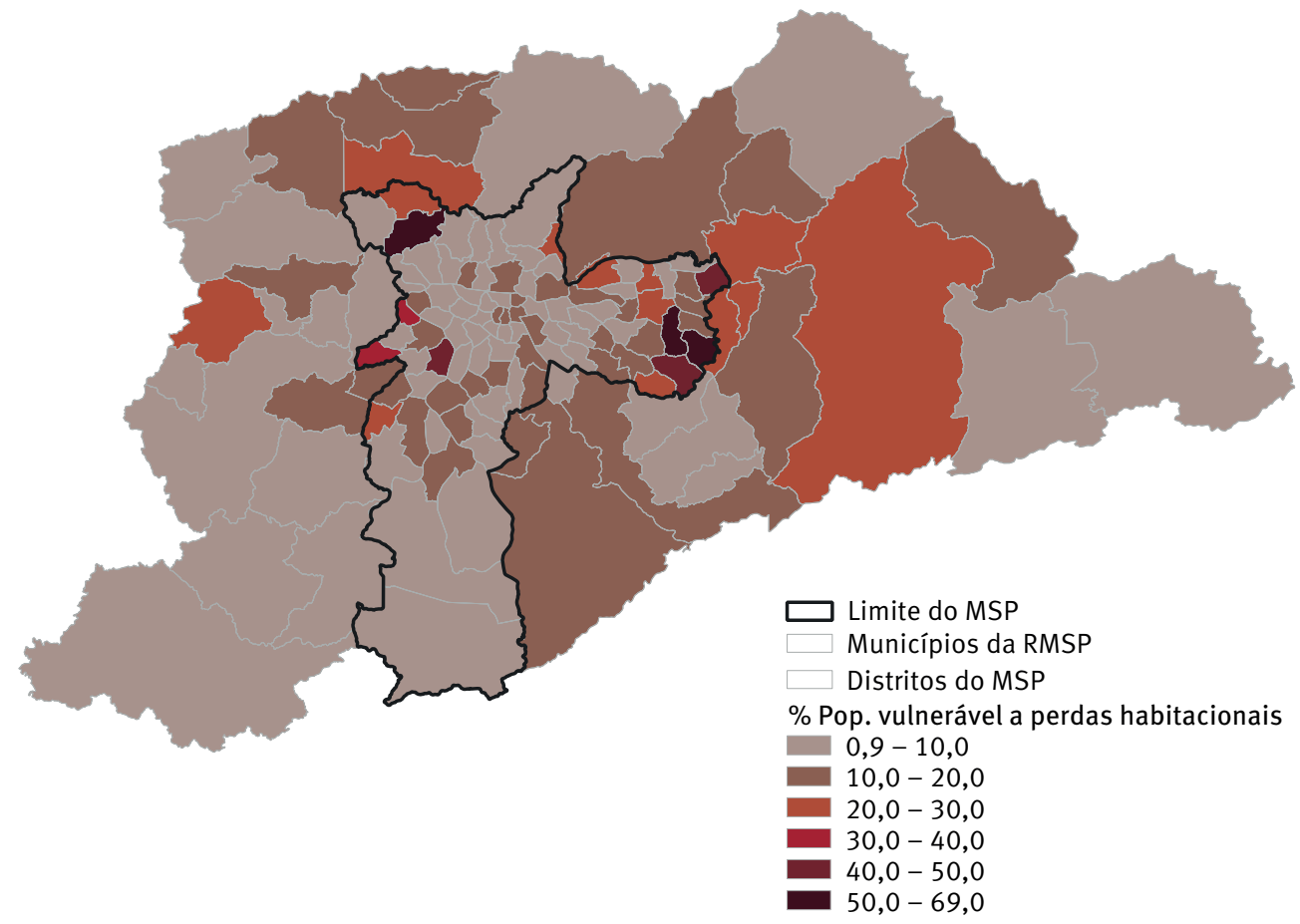

Fonte: IBGE. Censo Demográfico 2010. 
Nos demais municípios da RMSP, como Caieiras, na porção noroeste, Itapevi, na oeste, e Ferraz de Vasconcelos, Itaquaquecetuba, Mogi das Cruzes e Poá, na leste, é possível que os percentuais entre $30 \%$ e $40 \%$ da população “deslocalizável” e vulnerável a perdas habitacionais que vivam em domicílio particular permanente "próprio de algum morador - ainda pagando" viviam em habitações adquiridas em loteamentos populares, regulares ou não, ou em conjuntos habitacionais da CDHU.

\section{Moradores “deslocalizáveis" e vulneráveis em domicílios particulares permanentes alugados}

A teia da insegurança habitacional formada pelo entrelaçamento entre a "deslocabilidade" e a vulnerabilidade diante dos riscos de perdas habitacionais, da "alienação residencial" e dos processos de remoção de moradores de baixa renda dos seus locais de moradia envolve também os moradores dos domicílios particulares permanentes "alugados". No senso comum, esses moradores são vistos como os mais “deslocalizáveis” e vulneráveis a perdas habitacionais, pois faz parte do imaginário social a ideia de que os proprietários de imóveis alugados têm todo o direito de mover ações de despejo contra seus inquilinos que porventura venham a atrasar ou deixar de fazer os pagamentos dos aluguéis. Há motivos históricos, jurídicos e factuais para o estabelecimento de ligações diretas entre o atraso ou qualquer outro descumprimento em relação ao pagamento de aluguel e as ações de despejos que obrigam os inquilinos devedores a saírem do imóvel alugado e, nos casos das moradias, a sofrerem perdas habitacionais e consequente “deslocalização”. Portanto, é inevitável considerar os moradores de baixa renda que vivem em moradias alugadas como parte da população “deslocalizável” e vulnerável a perdas habitacionais.

As análises clássicas sobre a gentrificação elaboradas por Ruth Glass (2010) ${ }^{10}$ a partir das mudanças sociodemográficas e imobiliárias verificadas no centro de Londres durante a década de 1960 mostraram os impactos desse fenômeno urbano sobre os inquilinos e locatários habitacionais de baixa renda.

Em sua proposta para uma teoria da gentrificação baseada na economia política da produção e transformação do espaço urbano, Neil Smith (2010) destaca a importância dos determinantes da “depreciação do capital” (capital depreciation) na produção da disparidade entre a renda fundiária potencial e a atual (rent gap), sendo esta última capitalizada sob o uso presente da terra urbana. Para Smith (2010, p. 81, tradução nossa), aquela “depreciação (do capital imobiliário) produz as condições econômicas objetivas que faz com

\footnotetext{
${ }^{10}$ Ruth Glass foi a primeira pessoa a utilizar o termo "gentrification" em textos publicados na década de 1960. A autora empregou esse termo para se referir ao deslocamento (displacement) da classe trabalhadora que vivia em bairros centrais de Londres que, desse modo, sofria mudanças em seu caráter social (social character). Para Glass, a gentrification ocorria em um contexto de disputa e competição social e econômica pelo espaço urbano. Vale chamar a atenção para a diferença entre os termos "deslocamento", baseado na palavra "displacement" utilizada por Ruth Glass, e "deslocabilidade”, usado no presente trabalho a partir da palavra "displaceability" empregada por Oren Yiftachel. De acordo com este autor, "The documentation and analysis of evictions and displacements - important as they surely are - may not be enough for a new critical conceptualization of the contemporary city. I suggest here that an additional step should frame the phenomenon within the broader condition of displaceability”(YIFTACHEL, 2017).
} 
que a revalorização do capital (gentrificação) seja uma resposta racional do mercado". ${ }^{11}$ Dentre os fatores que participam da "depreciação do capital” imobiliário no centro da cidade, Smith inclui os fatores relacionados com o mercado de locação imobiliária, particularmente habitacional (landlordism). Em áreas impactadas pela gentrificação, aqueles inquilinos e locatários habitacionais de baixa renda podem sofrer pressões provocadas por aumentos nos valores dos aluguéis de suas habitações. Tais pressões podem surgir também quando os proprietários dessas habitações alugadas calculam possibilidades de ganhos maiores com o imóvel trazidas pela valorização produzida por aquele ciclo de reinvestimentos urbanos.

Hamnett e Randolph são os estudiosos que teorizaram sobre a gentrificação considerando os ganhos potenciais relacionados com a dinâmica do mercado de locação habitacional. Segundo Lees et al. (2008), aqueles dois autores complementam a teoria proposta por Neil Smith baseada no rent gap, propondo uma teoria sobre a gentrificação baseada em um outro tipo de gap que aparece nos dois métodos de avaliação da propriedade residencial utilizados na Inglaterra: um método baseado nos ganhos financeiros potenciais que podem vir a ser obtidos com o aluguel do imóvel habitacional; e outro baseado no valor deste imóvel quando estiver vago e, portanto, disponível para ser vendido no futuro para algum comprador que o adquire com a intenção de ocupá-lo e utilizá-lo. A disparidade entre os ganhos obtidos com a cobrança do aluguel e com a venda do imóvel é denominada por Hamnett e Randolph (1986 apud LEES et al., 2008, p. 69) como value gap. Se os ganhos com a cobrança do aluguel se mostrarem desvantajosos em relação aos ganhos que podem ser obtidos com a venda do imóvel, o locador pode optar por essa segunda alternativa e os inquilinos e locatários podem vir a ser despejados. Se ocorrer o contrário, isto é, nos casos em que os ganhos com o aluguel forem mais vantajosos, é certo que o acesso ao imóvel não é viável para inquilinos de baixa renda. Caso estes estejam alugando o imóvel para nele morar, certamente serão despejados e substituídos por inquilinos com maior poder aquisitivo e capacidade de pagamento.

Assim, tanto as teorias clássicas da gentrificação formuladas por Ruth Glass e Neil Smith quanto a de Hamnett e Randolph colocam-se como referências importantes para a seleção dos microdados relativos aos moradores de baixa renda (com renda familiar de até $R \$ 1.600,00$ ) de domicílios particulares permanentes alugados que foram utilizados na estimativa da população "deslocalizável” e vulnerável a perdas habitacionais. Nesta estimativa, os moradores de domicílios alugados representam $54 \%$ (1.848.285 pessoas) da população “deslocalizável” e vulnerável a perdas habitacionais residente na RMSP.

O Mapa 3 traz a distribuição desses moradores entre os municípios da RMSP e os distritos do MSP. Nota-se que os municípios da periferia metropolitana, onde mais de $50 \%$ da população “deslocalizável” e vulnerável vive em domicílios particulares permanentes alugados, apresentam forte conurbação com a área urbanizada do município de São Paulo.

\footnotetext{
${ }^{11}$ No original em inglês: "depreciation produces de objective economic conditions that make capital revaluation (gentrification) a rational market response".
} 
Observa-se, também, que a maioria dos distritos do MSP, tanto centrais quanto periféricos, tinha mais de $50 \%$ das suas populações vulneráveis a perdas populacionais estimadas em domicílios alugados. Em alguns distritos das porções intermediárias e do nordeste e noroeste do MSP, esse percentual é ainda maior, superando 75\%. Já nos distritos dos extremos da Zona Leste ocorre o oposto, pois tal percentual é inferior a $25 \%$. Conforme visto anteriormente, em alguns desses distritos com forte presença de conjuntos habitacionais de interesse social produzidos pelo poder público predomina a parte da população vulnerável a perdas habitacionais estimada que mora em domicílio particular permanente "próprio de algum morador - ainda pagando".

\section{MAPA 3}

Distribuição da população “deslocalizável” e vulnerável a perdas habitacionais em domicílios particulares permanentes alugados

Região Metropolitana de São Paulo - 2010

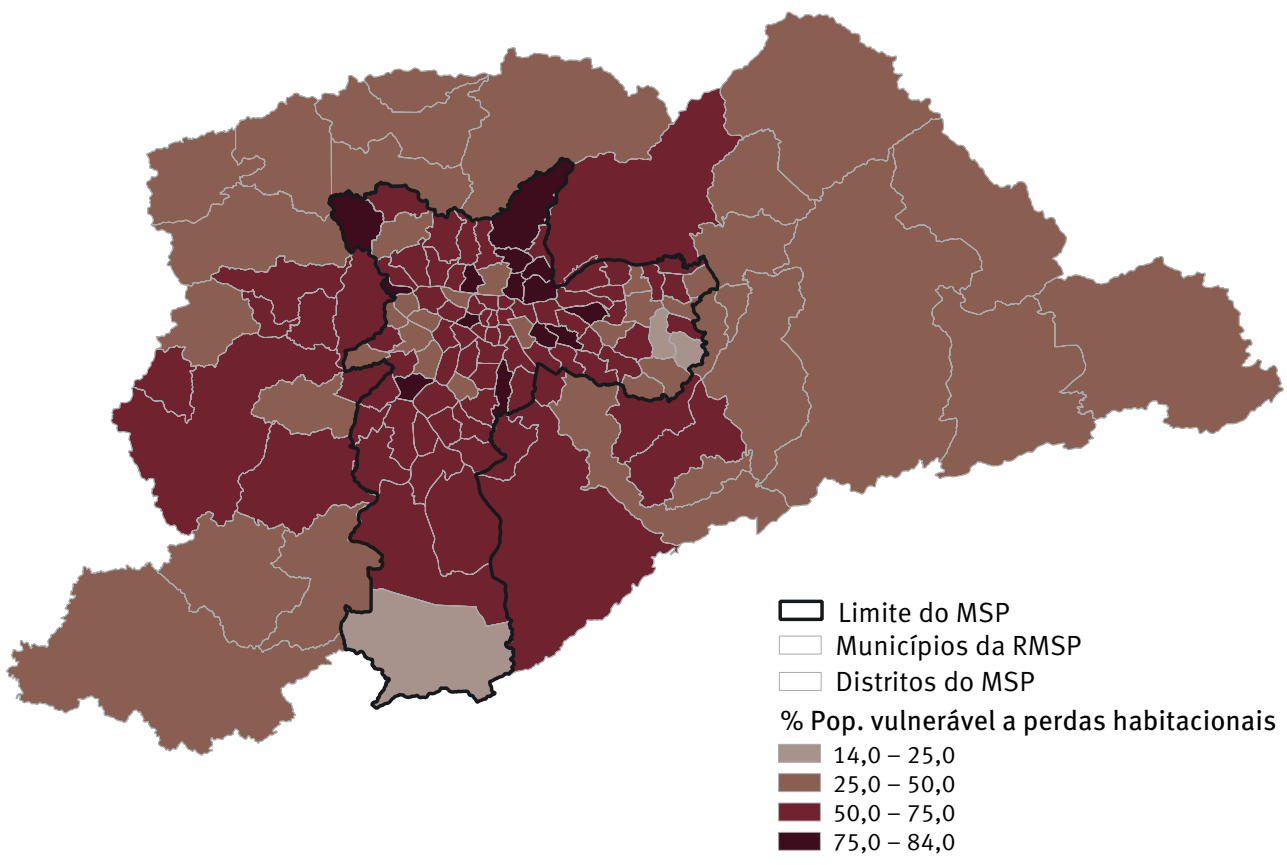

Fonte: IBGE. Censo Demográfico 2010.

Vale retomar o dado que indica a predominância das pessoas com baixos rendimentos que vivem em domicílios particulares permanentes alugados na estimativa da população “deslocalizável” e vulnerável a perdas habitacionais (54\%), pois, ao se inserirem em contextos urbanos caracterizados por valorizações fundiárias e imobiliárias decorrentes de investimentos públicos e/ou privados, podem vir a sofrer com a “deslocalização” e perda habitacional provocada por aumentos dos preços dos aluguéis residenciais. Conforme visto nos referenciais teóricos sobre a gentrificação mencionados anteriormente, os moradores da classe trabalhadora que vivem em domicílios alugados são um dos primeiros a sofrerem 
os impactos do rent gap produzido pelos ciclos de desinvestimentos e reinvestimentos, conforme Neil Smith (2010), e os efeitos do value gap, conforme Hamnett e Randolph (1986, apud LEES et al., 2008).

A dispersão espacial da população “deslocalizável” e vulnerável a perdas habitacionais moradora de domicílios particulares permanentes alugados por grande parte da área urbana metropolitana consolidada, inclusive em quase toda a área urbana do MSP, nos faz pensar que é necessário identificar os territórios onde estejam em curso, por exemplo:

- ocorrências de ações públicas causadoras de fortes valorizações fundiárias e imobiliárias, tais como melhorias nas condições de acessibilidade e mobilidade e implantação de grandes equipamentos e infraestruturas urbanas;

- incidências diretas dos investidores do mercado de incorporação imobiliária interessados na aquisição de imóveis destinados a receber novos empreendimentos;

- situações (reais ou não) de riscos geológicos e hidrológicos que podem ser utilizadas como justificativas para ações de remoção, “deslocalização”, despossessão e perda habitacional;

- fricções e conflitos entre moradores das camadas sociais de baixa, média e alta renda.

Nos contextos urbanos marcados por esses processos, os moradores de domicílios particulares permanentes alugados incluídos na estimativa da população "deslocalizável” e vulnerável a perdas habitacionais podem sofrer com aumentos nos preços de aluguéis residenciais e serem obrigados a se mudar dos seus locais de moradia. Nos casos de atraso ou inadimplência no pagamento dos aluguéis das suas moradias, podem vir a sofrer ações de despejo.

Moradores "deslocalizáveis" e vulneráveis em domicílios particulares permanentes cedidos pelo empregador, cedidos de outra forma e em outra condição de ocupação

Após justificar a adoção dos pressupostos relacionados com "deslocabilidade” e vulnerabilidade a perdas habitacionais dos moradores de domicílios particulares permanentes com condições de ocupação "próprio de algum morador - ainda pagando" e "alugado", faz-se necessário expor e justificar os pressupostos utilizados na seleção dos microdados relativos aos moradores de domicílios "cedidos pelo empregador", "cedidos de outra forma” ou ocupados em "outra condição", inclusive irregularmente. Por causa dos vínculos supostamente frágeis desses moradores de baixa renda com suas respectivas moradias cedidas e com outras condições de ocupação, nos termos utilizados pelo IBGE, pressupõe-se que tais moradores pobres também se encontram enredados na teia de riscos, inseguranças e ameaças de despossessão, “deslocabilidade” e perdas habitacionais mencionadas anteriormente e, portanto, vivam em constante "alienação residencial", no sentido proposto por David Madden e Peter Marcuse (2016).

Em geral, viver em uma habitação cedida por terceiros ou ocupada de modo precário e irregular indica insegurança e precariedade na ocupação e posse do imóvel habitacional. 
Pressupõe-se que o morador de baixa renda que vive em uma habitação cedida ou ocupada irregularmente possui pouco ou nenhum controle sobre a sua permanência nessa habitação. Eventuais conflitos ou rupturas na relação daquele morador com o proprietário ou locatário dessa habitação cedida ou ocupada em outra condição podem ocasionar a expulsão desse morador do seu local de moradia. Por isso, na seleção dos microdados utilizados na estimativa da população “deslocalizável” e vulnerável a perdas habitacionais, pressupôs-se que os moradores com renda familiar mensal de até $\mathrm{R} \$ 1.600,00$ que viviam em domicílios particulares permanentes “cedidos por empregador" ou "cedidos de outra forma" estavam sujeitos àquele tipo de vulnerabilidade e deveriam ser incluídos na estimativa populacional. Na estimativa da população “deslocalizável” e vulnerável a perdas habitacionais residente na RMSP, os moradores desses tipos de domicílios representam, respectivamente, $3 \%$ (192.297 pessoas) e 19,2\% (656.483 pessoas).

O Mapa 4 apresenta a distribuição de parte da população vulnerável a perdas habitacionais que mora em domicílios particulares permanentes cedidos por seus empregadores. A participação dos moradores desses domicílios na estimativa daquela população é muito baixa (3\%). Ainda observando o Mapa 4, vale destacar os municípios da periferia metropolitana onde o percentual supera $20 \%$. São municípios com fortes características rurais localizados nos extremos sudoeste (Juquitiba e São Lourenço da Serra), leste (Biritiba-Mirim, Guararema e Salesópolis), noroeste (Santa Isabel) e norte (Mairiporã). É bem provável que os moradores de domicílios particulares permanentes cedidos por seus empregadores nesses municípios e incluídos na estimativa da população "deslocalizável" e vulnerável a perdas habitacionais sejam caseiros que vivem nas propriedades rurais dos seus patrões. A mesma afirmação vale para o distrito periférico de Marsilac localizado no extremo sul do MSP. Na capital paulista, nota-se que os distritos centrais e intermediários de Jardim Paulista, Lapa, Moema, Pinheiros e Santo Amaro, onde há vários bairros das camadas de alta renda, o percentual da população “deslocalizável” e vulnerável a perdas habitacionais moradora de domicílios particulares permanentes cedidos por empregadores supera o patamar de $10 \%$. É provável que, nesses distritos, parte dessa população seja composta por empregadas domésticas e zeladores que vivem em seus locais de trabalho, nas residências dos patrões e patroas e nos condomínios residenciais verticais.

O Mapa 5 mostra a distribuição, dentre os municípios da RMSP e distritos do MSP, de parte da população “deslocalizável” e vulnerável a perdas populacionais composta pelos moradores de baixa renda que vivem em domicílios particulares permanentes cedidos de forma distinta da cessão por empregador. Conforme mencionado anteriormente, esses moradores que vivem em domicílios cedidos, provavelmente, por parentes, amigos, conhecidos, instituições, dentre outros, representam 19,2\% da população “deslocalizável” e vulnerável a perdas habitacionais. Nota-se que na maior parte dos municípios da periferia metropolitana esse percentual supera $20 \%$. Possivelmente, os bairros populares desses municípios possuem muitos moradores que vivem nos conhecidos "puxadinhos" cedidos por parentes, amigos, conhecidos e instituições. 
Vale indagar se parte significativa dos moradores de domicílios cedidos por terceiros que não são seus empregadores faz parte de famílias conviventes secundárias e vive em coabitação domiciliar conforme as definições adotadas pelo IBGE. Para responder a essa questão, é preciso verificar a participação desses moradores no universo da população “deslocalizável” e vulnerável a perdas habitacionais. Em 2010, essa participação era de 6,14\%, o que corresponde a 40.297 pessoas. Nota-se que, no cômputo geral, os membros de famílias conviventes secundárias em coabitação domiciliar não representavam parcela significativa no subgrupo da população “deslocalizável” e vulnerável à perda habitacional correspondente às pessoas de baixa renda em domicílios particulares permanentes cedidos de forma distinta da cessão por empregador. Contudo, é possível que em distritos e municípios metropolitanos mais periféricos, onde é comum a existência de lotes populares com várias moradias ocupadas por diferentes famílias, haja presença maior de pessoas em coabitação domiciliar.

MAPA 4

População “deslocalizável” e vulnerável a perdas habitacionais em domicílios particulares permanentes cedidos por empregadores

Região Metropolitana de São Paulo - 2010

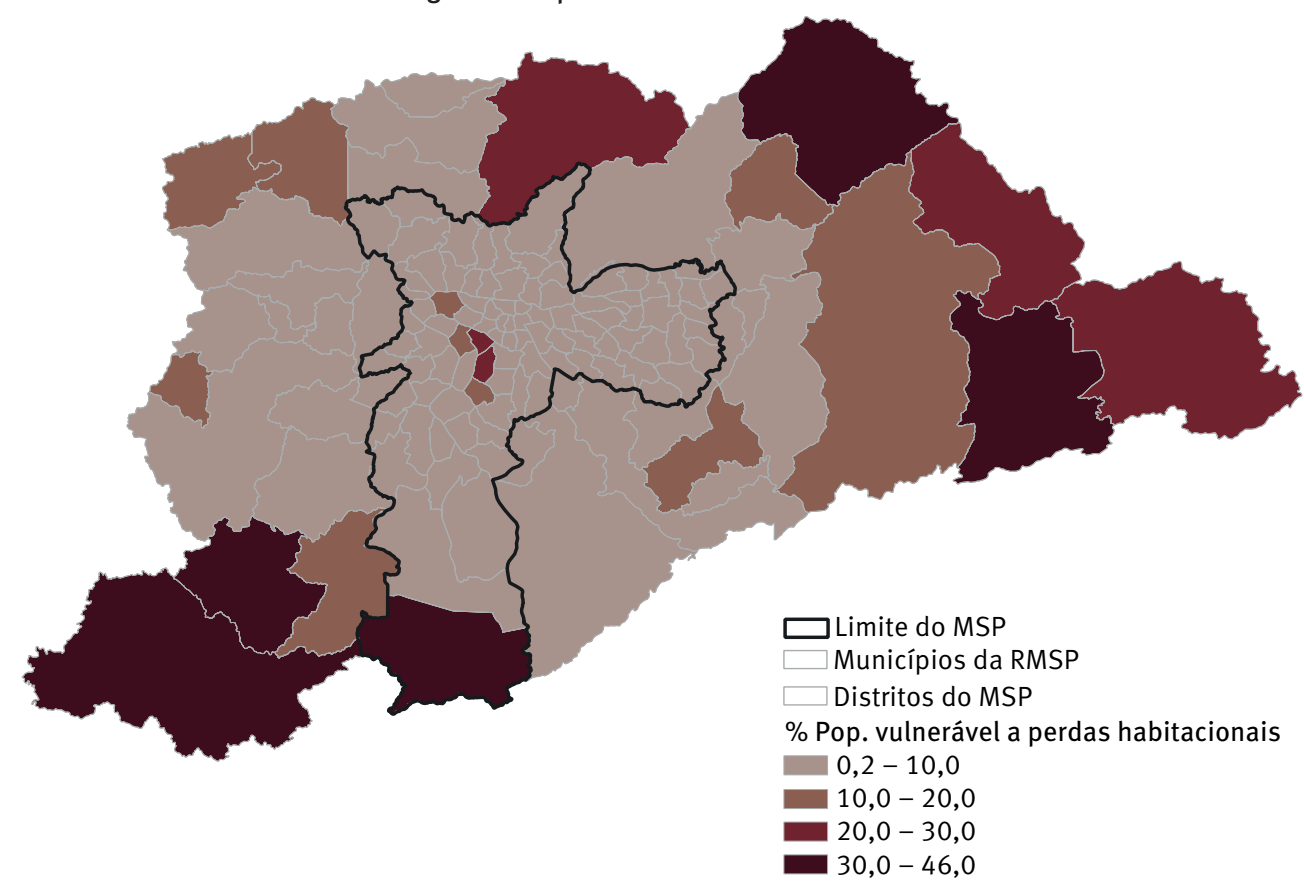

Fonte: IBGE. Censo Demográfico 2010.

Ainda no Mapa 5 nota-se que, entre os distritos do MSP, predominam aqueles onde os percentuais da população vulnerável a perdas habitacionais em domicílios particulares permanentes cedidos de outra forma encontram-se na faixa entre $10 \%$ e $20 \%$. Com exceção de Iguatemi, localizado no extremo da periferia leste, os distritos onde esse percentual é inferior a $10 \%$ situam-se nas porções mais bem localizadas e com melhores condições urbanas do centro expandido. 


\section{MAPA 5}

Distribuição da população vulnerável a perdas habitacionais em domicílios particulares permanentes cedidos de outra forma

Região Metropolitana de São Paulo - 2010

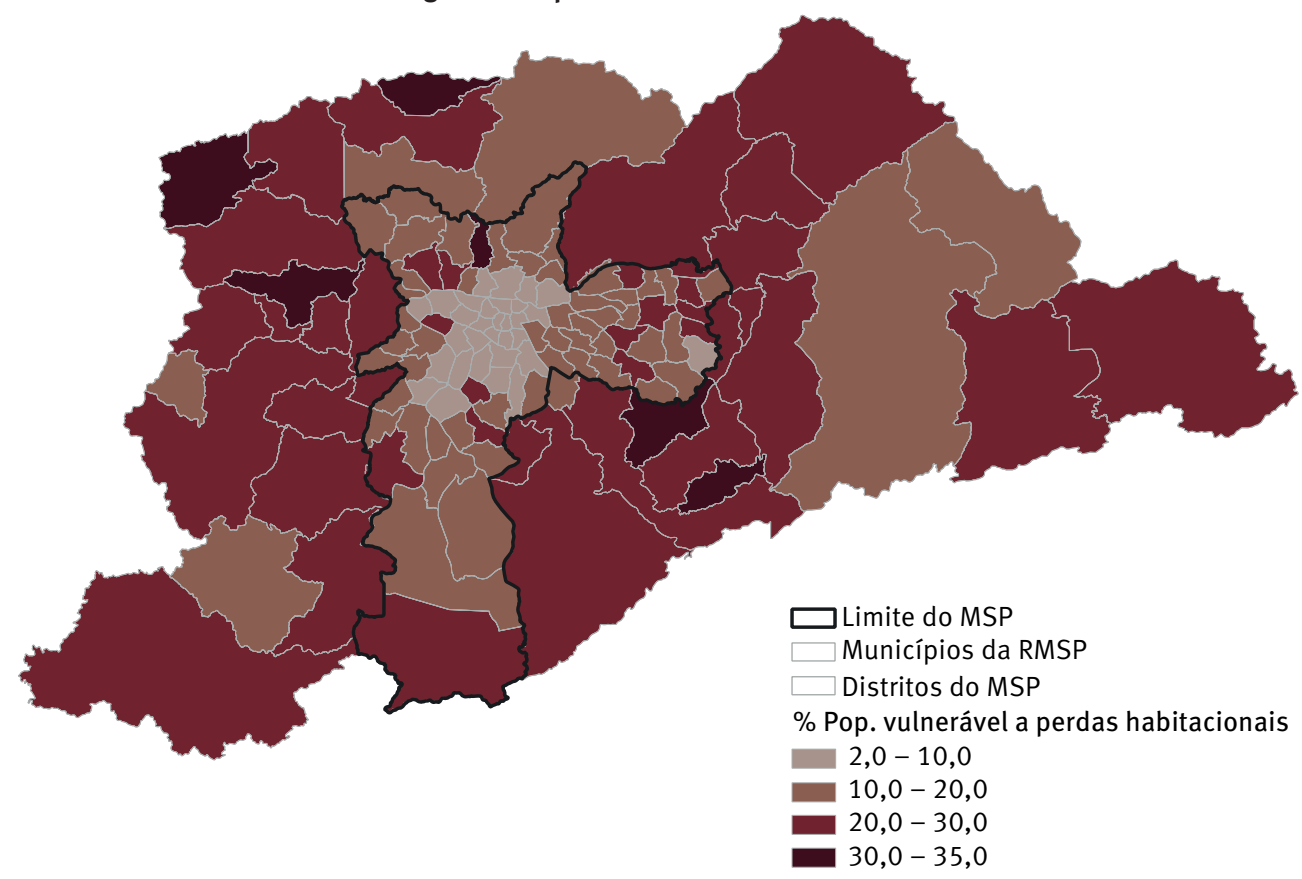

Fonte: IBGE. Censo Demográfico 2010.

A parcela da estimativa da população vulnerável a perdas habitacionais composta pelos moradores de domicílios particulares permanentes com outras condições de ocupação representa $6,3 \%$ (216.417 pessoas) do total. Nessas condições de ocupação domiciliar incluem-se "unidade domiciliar em conjunto com unidade não residencial” e também “domicílio ocupado por invasão" (IBGE, 2010, p. 6).

No Mapa 6, observa-se que esses moradores concentram-se em poucos municípios da RMSP e distritos do MSP, dentre os quais predominam aqueles com menos de $10 \%$ da população vulnerável a perdas habitacionais que mora em domicílios particulares permanentes com condições de ocupação que se distinguem daquelas vistas até agora. Os municípios da RMSP onde esse percentual é superior a 10\% são Carapicuíba, Embu das Artes e Santana de Parnaíba, localizados a oeste, e Guarulhos e Itaquaquecetuba, a leste. Muito provavelmente, esse mais elevado percentual deve-se à presença maior de moradores em domicílios “ocupados por invasão”, pois, nesses municípios, as ocupações irregulares de terras ociosas por grupos de pessoas de baixa renda com necessidades habitacionais são comuns, principalmente em áreas mais periféricas. 


\section{MAPA 6}

Distribuição da população vulnerável a perdas habitacionais em domicílios particulares permanentes com outras condições de ocupação

Região Metropolitana de São Paulo - 2010

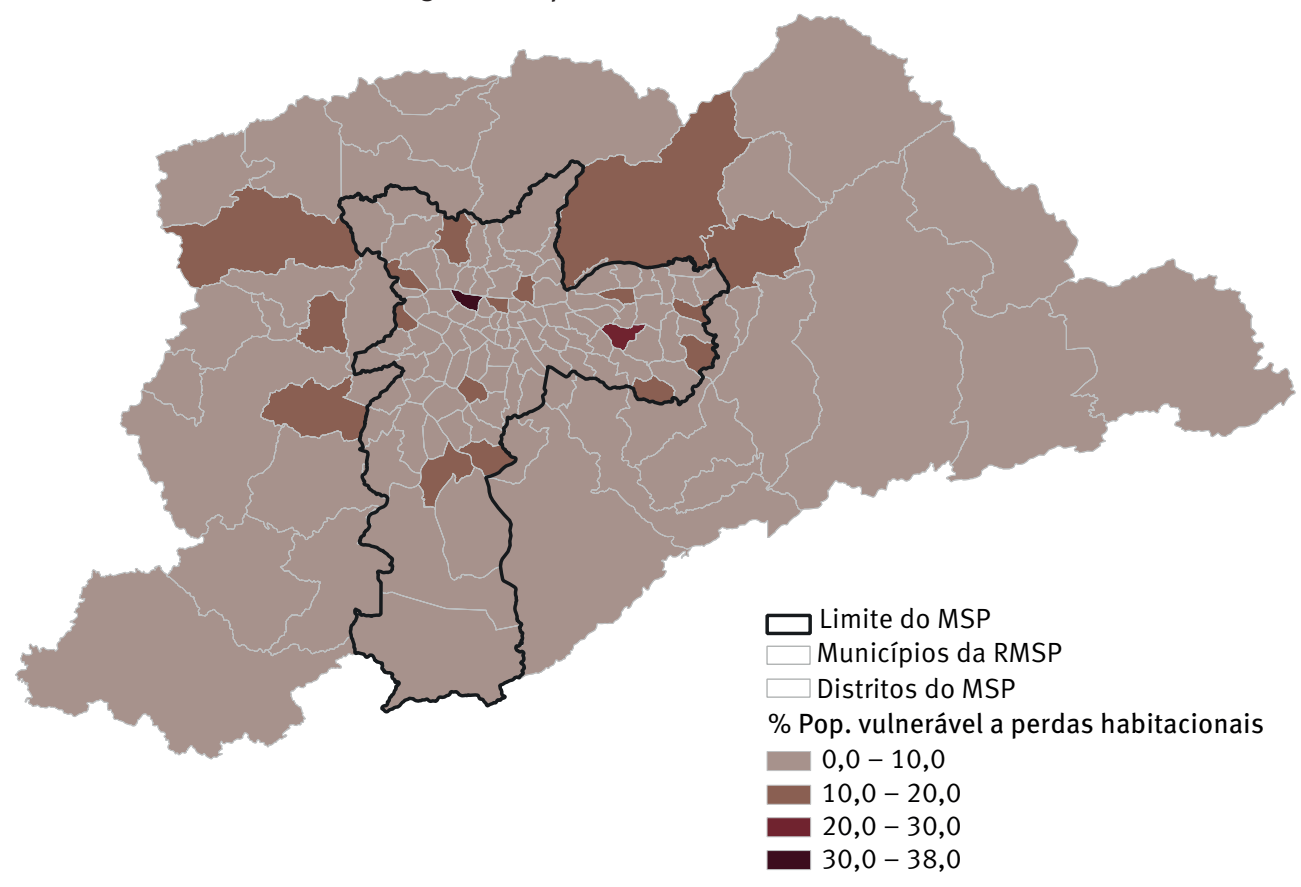

Fonte: IBGE. Censo Demográfico, 2010.

Provavelmente, a presença dos moradores de domicílios "ocupados por invasão" também explica os distritos do MSP mais periféricos com mais de $10 \%$ da população vulnerável a perdas habitacionais que moram em domicílios particulares permanentes com condições de ocupação que se distinguem daquelas vistas até agora. Já nos distritos mais centrais da Barra Funda, Bom Retiro e Vila Guilherme, os percentuais mais altos podem ser explicados pela presença de moradores em "unidade domiciliar em conjunto com unidade não residencial”. Isso porque, nessas áreas, existem muitas moradias ligadas a estabelecimentos comerciais e de serviços, com destaque para Barra Funda, onde tal percentual supera os $30 \%$. No Bom Retiro, é conhecida a existência de moradores que vivem em domicílios acoplados a confecções, muitos deles imigrantes da China e Coreia do Sul. É provável que boa parte desses moradores integrem a estimativa da população vulnerável a perdas habitacionais. 


\section{Estimativa da população vulnerável a perdas habitacionais na Região Metropolitana de São Paulo}

Recapitulando, a estimativa da população vulnerável a perdas habitacionais residente na RMSP (3.423.265 pessoas) resulta da somatória entre:

- os moradores com renda familiar menor ou igual a $\mathrm{R} \$ 1.600,00$ que residem em domicílios particulares permanentes próprios de algum morador - ainda pagando (518.471 pessoas, correspondentes a $15,1 \%$ do total), alugados (1.848.285 pessoas, equivalentes a $54 \%$ ), cedidos por empregadores (102.297 pessoas, 3,0\%), cedidos de outra forma (653.483 pessoas, 19,2\%) e em outras condições de ocupação (216.417 pessoas, 6,3\%);

- os moradores que residem em domicílios particulares improvisados instalados em tendas ou barracas, dentro de estabelecimentos não residenciais e de outros tipos (11.279 pessoas, correspondentes a 0,3\%);

- os moradores que residem em domicílios coletivos instalados em: asilo, orfanato e similares; hotel, pensão e similares; alojamento de trabalhadores; e penitenciária, presídio e casa de detenção (70.033 pessoas, correspondentes a 2,0\%).

O Mapa 7 apresenta a distribuição da população estimada vulnerável a perdas habitacionais dentre os municípios da RMSP e os distritos do MSP. Percebe-se que os municípios da periferia metropolitana com mais de $20 \%$ das suas populações em suposta situação de vulnerabilidade a perdas habitacionais estão, em sua maioria, nas bordas leste, nordeste, noroeste e sudoeste da metrópole paulistana e, também, são contíguos aos extremos da Zona Leste do município de São Paulo, onde está praticamente um terço dos distritos paulistanos (sete distritos) que também apresentam mais de $20 \%$ daquelas populações. Alguns desses distritos paulistanos estão nas porções mais antigas do centro da cidade (Bom Retiro, Brás, Pari, República e Sé).

Os distritos com menos de $10 \%$ dos residentes supostamente vulneráveis a perdas habitacionais localizam-se a oeste e sudoeste do centro antigo. É interessante observar que parte dos distritos com baixos percentuais localiza-se no chamado "quadrante sudoeste", delimitado pelas calhas dos rios Tietê (a norte), Pinheiros (a oeste) e Tamanduateí (a leste) e pela avenida Cupecê (a sul), conhecido por seus bairros de média e alta renda, pela concentração da maior parte dos empregos formais da metrópole, por suas boas condições urbanas e habitacionais, pelas oportunidades de consumo, lazer e cultura e pelas provisões adequadas de serviços, equipamentos e infraestruturas urbanas.

Verifica-se, ainda, que nas porções norte e leste do "quadrante sudoeste", junto aos rios Tietê e Tamanduateí, respectivamente, há distritos com 10\% a 20\% das suas populações consideradas vulneráveis a perdas habitacionais, inclusive os já mencionados distritos do centro antigo. É importante notar também que em distritos fora desse quadrante, localizados para além dos rios Tietê (Santana - Zona Norte), Pinheiros (Morumbi, 
Socorro e Vila Andrade - Zona Oeste) e Tamanduateí (Tatuapé - Zona Leste) e da avenida Cupecê (Campo Grande - Zona Sul), encontram-se os vetores das frentes de expansão da produção imobiliária destinada às classes média e alta. Esses vetores são formados por empreendimentos imobiliários residenciais verticais e articulam ações e investimentos públicos e privados que, muitas vezes, revolvem as configurações territoriais, fazendo com que as populações vulneráveis sofram efetivamente as perdas habitacionais anunciadas, em estado virtual, no presente trabalho.

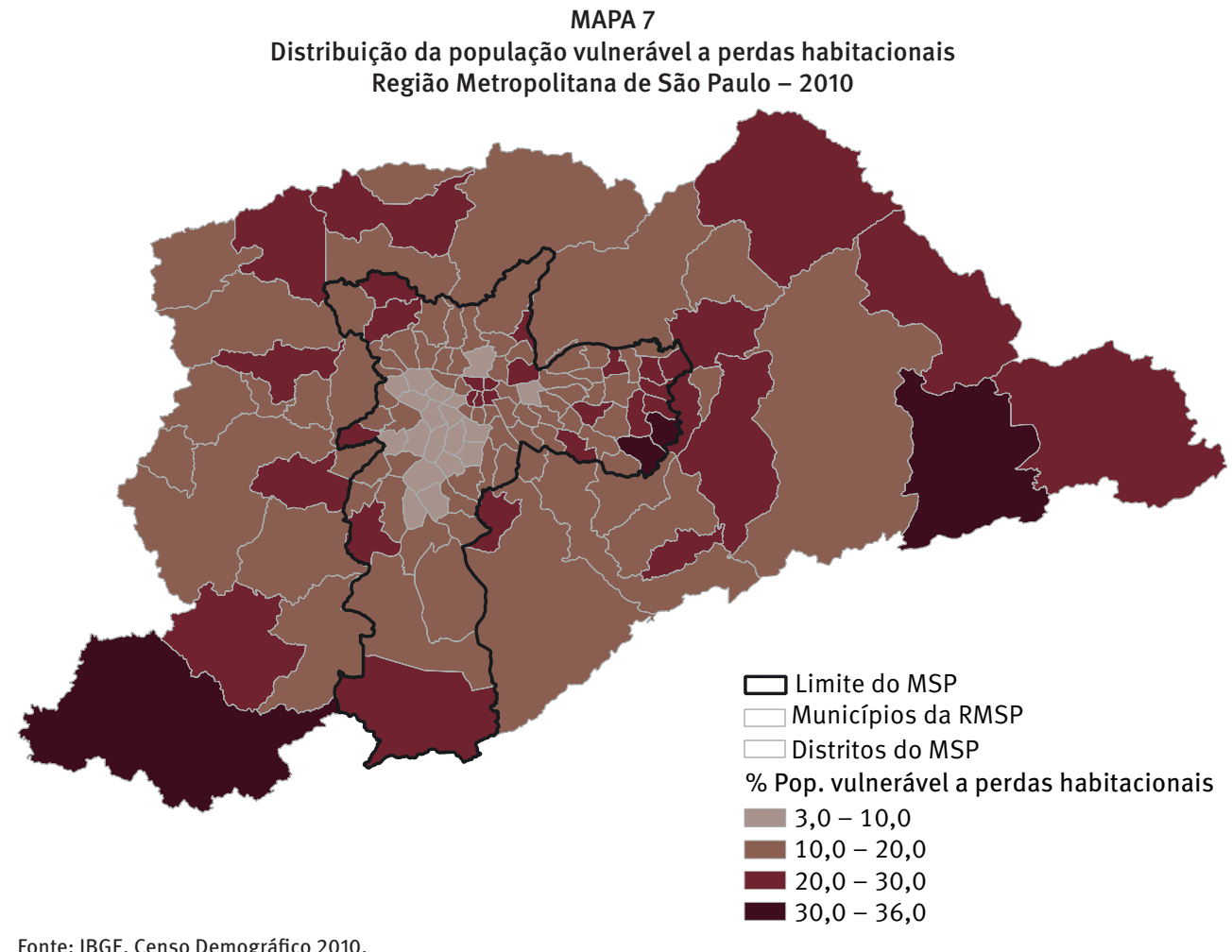

Fonte: IBGE. Censo Demográfico 2010.

\section{Considerações finais}

Esse trabalho apresenta a estimativa da população vulnerável a perdas populacionais residente na RMSP. Os moradores de baixa renda (com renda familiar menor ou igual a $\mathrm{R} \$ 1.600,00$ ) de domicílios particulares permanentes (classificados segundo condições de ocupação domiciliar), particulares improvisados e coletivos, pesquisados na amostra censitária de 2010, compõem essa estimativa. Dentre os moradores de baixa renda, destacam-se os que residem em domicílios particulares permanentes alugados, cedidos de outra forma e próprios de algum morador e ainda não quitados que representam, respectivamente, $54 \%, 19,2 \%$ e 15,1\% da população estimada vulnerável a perdas habitacionais. 
Determinadas condições de ocupação domiciliar tornam moradores vulneráveis a perdas habitacionais porque estes não possuem as capacidades e condições necessárias para mobilizar recursos que os ajudem a enfrentar os impactos de processos diversos de despossessão territorial. No contexto da urbanização capitalista financeirizada atual, tais processos podem ser mais agressivos e se encontram cada vez mais disseminados por praticamente toda a área urbanizada da metrópole. Isso torna os contextos urbanos da metrópole paulistana cada vez mais conflituosos, pois em muitos lugares surgem processos de contra-despossessões territoriais levados a cabo por moradores que resistem a perdas das suas moradias.

Diante de tal contexto, se faz urgente a necessidade de compreender criticamente a economia política geral das despossessões territoriais, perdas habitacionais e conflitos fundiários. Para isso, é importante articular os estudos gerais e específicos, as análises quantitativas e qualitativas e as abordagens estruturais e processuais.

\section{Referências}

ALVES, J. E. D.; CAVENAGHI, S. Questões conceituais e metodológicas relativas a domicílio, família e condições habitacionais. Papeles de Población, n. 43, p. 105-131, 2005. Disponível em: https://www.redalyc.org/articulo.oa?id=11204306. Acesso em: 15 fev. 2021.

FUNDAÇÃO JOÃO PINHEIRO. Déficit habitacional no Brasil - 2015. Belo Horizonte: Fundação João Pinheiro, 2018.

GLASS, R. Aspects of change. In: BROWN-SARACINO, J. (ed.). The gentrification debates. New York; London: Routledge, 2010. p. 19-29.

IBGE - INSTITUTO BRASILEIRO DE GEOGRAFIA E ESTATÍSTICA. Censo Demográfico 2010 Documentação. Rio de Janeiro, 2010. Disponível em: https://ww2.ibge.gov.br/home/estatistica/ populacao/censo2010/resultados_gerais_amostra/resultados_gerais_amostra_tab_uf_ microdados.shtm. Acesso em 07 jun. 2019.

KATZMAN, R.; FILGUEIRA, F. As normas como bem público e privado: reflexões nas fronteiras do enfoque "ativos, vulnerabilidade e estrutura de oportunidades" (Aveo). In: CUNHA, J. M. P. da (org.). Novas metrópoles paulistas - população, vulnerabilidade e segregação. Campinas, SP: Núcleo de Estudos de População - Nepo/Unicamp, 2006.

LEES, L.; SLATER, T.; WYLY, E. Gentrification. New York; London: Routledge, 2008.

MADDEN, D.; MARCUSE, P. In defense of housing - the politics of crisis. Londres; Nova York: Verso, 2016.

MOSER, C. O. N. Household responses to poverty and vulnerability - confronting crisis in Cisne Dos, Guayaquil, Ecuador. Washington: The World Bank, 1997.

NASCIMENTO, D. M.; BRAGA, R. C. de Q. Deficit habitacional: um problema a ser resolvido ou uma lição a ser aprendida? Risco - Revista de Pesquisa em Arquitetura e Urbanismo, n. 9, p. 98-108, 2009. DOI:10.11606/issn.1984-4506.v0i9p98-109. Disponivel em: https://www. revistas.usp.br/risco/article/view/44765. Acesso em: 14 fev. 2021.

OLIVEIRA, E. L. de; GIVISIEZ, G. H. N.; RIOS-NETO, E. L. G. Demanda futura por moradias no Brasil

2003-2023: uma abordagem demográfica. Brasília: Ministério das Cidades, 2009. 
ROLNIK, R. Guerra dos lugares - a colonização da terra e da moradia na era das finanças. São Paulo: Boitempo, 2016.

ROY, A.; ROLNIK, R. Metodologias de pesquisa-ação para promover a justiça habitacional. In: MOREIRA, F. A.; ROLNIK, R.; SANTORO, P. F. (org.). Cartografias da produção, transitoriedade e despossessão dos territórios populares. Relatório Bianual 2019-2020. São Paulo: Observatório das Remoções,2020.

SMITH, N. Toward a theory of gentrification: a back to the city movement by capital, not people. In: BROWN-SARACINO, J. (ed.). The gentrification debates. New York; London: Routledge, 2010. p. 71-85.

YIFTACHEL, O. Displaceability - a Southeastern perspective. 2017. Disponível em: http:// mitdisplacement.org/symposium-oren-yiftachel. Acesso em: 04 fev. 2021.

\title{
Sobre o autor
}

Anderson Kazuo Nakano é doutor em Demografia pelo Núcleo de Estudos de População "Elza Berquó, Instituto de Filosofia e Ciências Humanas, Universidade Estadual de Campinas (Nepo/ IFCH/Unicamp), mestre em Estruturas Urbanas e Ambientais pela Faculdade de Arquitetura e Urbanismo, Universidade de São Paulo (FAU/USP), pós-graduado em Gestão Municipal Ambiental pelo Institute for Housing and Urban Development-IHS de Rotterdan e arquiteto urbanista graduado pela FAU/USP.

\section{Endereço para correspondência}

Rua Alves Guimarães, 461, apartamento 112, Pinheiros

05410-000 - São Paulo-SP, Brasil

\begin{abstract}
Vulnerability to housing loss in the Metropolitan Region of São Paulo

The present work aims to estimate the population vulnerable to housing loss living in the Metropolitan Region of São Paulo (RMSP). For this purpose, we used microdata from the 2010 Demographic Census sample produced by the Brazilian Institute of Geography and Statistics (IBGE). Microdata related to family income, species and types of households and conditions of occupation of permanent private households are selected based on theoretical and conceptual premises related to displaceability (YIFTACHEL, 2017), housing insecurity and alienation, (MADDEN; MARCUSE, 2016), permanent transience (ROLNIK, 2015), gentrification and rent gap (SMITH, 2010) and gentrification and value gap (HAMNETT; RANDOLPH, 1986 in LEES et al., 2008). The estimated displaceable population vulnerable to housing loss living in the RMSP is $3,423,265$ people (2010).
\end{abstract}

Keywords: Displaceability. Vulnerability. Housing loss. Metropolitan Region of São Paulo. 


\section{Resumen}

Vulnerabilidad a la pérdida de vivienda en la Región Metropolitana de São Paulo

El presente trabajo tiene como objetivo estimar la población vulnerable a la pérdida de vivienda que vive en la Región Metropolitana de San Pablo(RMSP). Para ello se utilizan microdatos de la muestra del censo demográfico de 2010 del Instituto Brasileño de Geografía y Estadística (IBGE). Los microdatos relacionados con los ingresos familiares, las especies y los tipos de hogares y las condiciones de ocupación de los hogares privados permanentes se seleccionan en función de premisas teóricas y conceptuales relacionadas con la deslocabilidad (displaceability) (YIFTACHEL, 2017), inseguridad y alienación de la vivienda (MADDEN; MARCUSE, 2016), transición permanente (ROLNIK, 2015), gentrificación y rent gap (SMITH, 2010) y gentrificación y value gap (HAMNETT; RANDOLPH, 1986 in LEES et al., 2008). El cálculo de laestimación de lapoblación deslocalizable y vulnerable a la pérdida de vivienda que vive en la RMSP da como resultado 3.423.265 personas (2010).

Palabras clave: Deslocabilidad. Vulnerabilidad. Pérdida de la vivienda. Región Metropolitana de São Paulo.

Recebido para publicação em 13/05/2020

Aceito para publicação em 05/04/2021 